\title{
A Nation-Wide Survey of High School Baseball Coaches' Perceptions Indicates their Arm Care Programs Play a Role in Injury Prevention
}

\author{
K A Matsel $^{1}$ a, E E Weiss $^{2}$, R J Butler ${ }^{3}$, M C Hoch ${ }^{2}$, P M Westgate ${ }^{2}$, T R Malone $^{2}$, T L Uhl ${ }^{2}$ \\ 1 University of Kentucky; University of Evansville, ${ }^{2}$ University of Kentucky, ${ }^{3}$ Saint Louis Cardinals Baseball Organization \\ Keywords: movement system, injury prevention, baseball, arm care \\ https://doi.org/10.26603/001c.24247
}

\section{International Journal of Sports Physical Therapy}

Vol. 16, Issue 3, 2021

\section{Background}

Arm care programs consisting of upper extremity strengthening and stretching have been recommended for injury prevention for pitchers of all ages. There has been no investigation into high school baseball coaches' usage and perceptions of arm care programs to mitigate physical impairments associated with injuries in baseball players.

\section{Hypothesis/Purpose}

The purpose of this study was to investigate the current usage of arm care programs by high school baseball coaches. The primary objective was to determine if coaches use group-based or individualized arm care programs. The secondary objective sought to determine if the use of arm care programs is influenced by coaches' age, education, and experience level. Finally, this study explored the potential barriers to arm care implementation and high school baseball coaches' current awareness and beliefs of injury prevention.

\section{Study Design}

Descriptive cross-sectional survey

\section{Methods}

A 29-item online survey was emailed to 18,500 high school baseball coaches throughout the United States. Data were collected for three months, and the response rate was $3.7 \%$.

\section{Results}

A total of $87.3 \%(n=571 / 654)$ of responding coaches use arm care programs with their players. Of coaches performing arm care, only $18.5 \%$ of 571 individualize their arm care exercises based on specific player needs. However, older and more experienced coaches are more likely to individualize their programs. Among the $12.7 \%(n=83 / 654)$ of coaches who do not use arm care programs, the two most commonly cited reasons for not implementing arm care were lack of observed benefit (41\%) and insufficient staff (31\%). Although $42 \%$ of 654 coaches recognized reduced shoulder mobility as a major contributor to injury, risk factors such as throwing with a fatigued arm, previous injury history, and throwing $>8$ months per year were not consistently identified as primary risk factors.

\footnotetext{
a Corresponding author: 


\section{Conclusion}

The results of this study suggest that the majority high school baseball coaches implement group-based arm care exercise programs to prevent injury. Lack of confidence in the effectiveness and staffing limitations were major barriers to implementation of arm care programming. However, the responding coaches exhibited inconsistent risk factor awareness and dated injury prevention beliefs. Therefore, better educational collaboration between rehabilitation professionals and high school coaches regarding injury risk factors and preventative strategies is warranted.

\section{Level of Evidence}

Level 3

\section{INTRODUCTION}

Injuries to the shoulder and elbow are common among high school baseball pitchers. The incidence of experiencing elbow or shoulder pain in high school pitchers is 1.0 per 1000 athletic exposures (AEs) and 1.5 per 1000 AEs, respectively. ${ }^{1}$ The shoulder and elbow joint are exposed to tremendous stress during the throwing motion ${ }^{2-4}$ which is typically repeated hundreds of times during competition throughout the season. ${ }^{5-7}$ A number of risk factors, including range of motion (ROM) and strength limitations, ${ }^{8-13}$ high levels of throwing volume, $, 5,14-16$ and an increase in acute workload ${ }^{6,17}$ have been identified as contributing to increased arm soreness and time loss injuries. ${ }^{18}$ To combat these risk factors, researchers have focused on investigating compliance with pitch counts, ${ }^{19-22}$ number of rest days in between starts, ${ }^{21,23}$ managing yearly pitching volume, 19 discouraging pitching showcases, ${ }^{24}$ and playing catcher as secondary position. ${ }^{16}$ As a result, arm care programs, which typically consist of upper extremity strengthening and stretching, ${ }^{25}$ core stability, ${ }^{26}$ and management of pitching volume have been suggested as necessary components of injury prevention plans for pitchers of all ages. ${ }^{27}$

To reduce the risk of injury to the shoulder and elbow, the USA Baseball Medical \& Safety Advisory Committee (USA BMSAC) $^{28}$ and Major League Baseball established the Pitch Smart guidelines in 2014. ${ }^{29}$ These guidelines proposed age specific throwing limitations in an attempt to manage pitching volume, workload, and fatigue. However, understanding and compliance of these guidelines among baseball coaches have been underwhelming. ${ }^{22}$ In a 2018 survey of 61 baseball coaches, Knapik et $\mathrm{al}^{20}$ found that only $56 \%$ of coaches kept track of pitch counts routinely and only $43 \%$ reported compliance with age specific pitch count recommendations. Considering the poor compliance and knowledge relative to the Pitch Smart guidelines, it is reasonable to suggest that underutilization and awareness deficits regarding arm care programs could also be problematic. Knapik et al, ${ }^{20}$ reported that only $8 \%$ of the 61 baseball coaches surveyed could correctly identify risk factors that could lead to overuse injury. This lack of knowledge of physical risk factors makes designing effective arm care programs difficult.

When implemented, arm care programs have been shown to be effective at reducing overuse injuries to the elbow and shoulder in overhead athletes. ${ }^{30-33}$ In a randomized controlled trial, Sakata et $\mathrm{al}^{30}$ demonstrated a $48.5 \%$ reduction in elbow overuse injuries in youth baseball play- ers. Shitara et $\mathrm{al}^{32}$ reported that stretching the posterior shoulder muscles lowered the incidence of shoulder and elbow injuries by $36 \%$ in high school baseball pitchers. While these two studies showcase the potential effectiveness of arm care programs, there has been no investigation into high school baseball coaches' current usage and perceptions of arm care programs to improve physical impairments associated with the injury risk factors described above.

To date, the authors are unaware of another study which has explored the application and characteristics of arm care programs from the perspective of the high school baseball coach. Therefore, the purpose of this study was to investigate if high school baseball coaches are using arm care programs to promote shoulder and elbow health for their players. The primary objective was to determine if high school baseball coaches are implementing generalized groupbased programs or individualized arm care based on the specific needs of the player. It was hypothesized that less than $50 \%$ of high school coaches who implement arm care exercises will use individualized programs. The secondary objective was to investigate if the use of arm care programs is influenced by coaches' age, education, and experience level. It was hypothesized that older coaches with more education and experience will be more likely to implement individualized arm care exercises. Finally, this study explored potential barriers to arm care implementation and high school baseball coaches' current awareness and beliefs associated with injury prevention. It was hypothesized that limited time and resources would be identified as common barriers to arm care implementation and that high school coaches would demonstrate limited knowledge of important injury risk factors.

\section{METHODS}

\section{SURVEY DEVELOPMENT}

This was a descriptive, cross-sectional study which evaluated the current application and characteristics of arm care programs and injury prevention concepts in high school baseball coaches. An electronic survey (Appendix 1) was developed in Qualtrics (electronic data capture tools hosted at the University of Kentucky) based on the current literature involving injury prevention exercise programs in adolescent baseball players. The survey was created by two rehabilitation professionals (KAM and TLU) with multiple years of clinical and research experience in baseball. The survey contained 29-items which were represented in three sec- 
tions including, 1) demographics/coaching experience, 2) characteristics and application of arm care programs, and 3) knowledge and beliefs of injury prevention measures.

The first section consisted of five questions related to demographic information such as the participant's age, education level, and coaching experience. Additional questions in this section were related to the age and competition level (school team, recreational league, or traveling team) of the baseball players the participant has coached. The second section had 17 questions which were designed to explore the application and characteristics of arm care programs among high school coaches. The questions in this section were specific to the design of arm care programs and examined the concepts of group versus individualized programs, goals, program components, frequency of performance per week, time allocated to specific exercises and body regions, and barriers to implementation. The third section had seven questions which were designed to determine the high school coaches' knowledge and current beliefs related to injury prevention. The questions in this section asked about injury risk factors specific to baseball players, effectiveness of arm care programs related to injury incidence reduction, and whether or not risk factors should be monitored throughout the season.

Prior to nationwide distribution, the intra-rater reliability of the survey was assessed in a sample of 11 baseball coaches. Each coach completed the survey twice with a 10-day washout period in-between and absolute intra-rater agreement was measured with a weighted Cohen's kappa statistic. The survey demonstrated excellent intra-rater absolute agreement with a weighted kappa value of 0.87 and excellent internal consistency with a Cronbach's alpha of 0.97. 34,35

\section{SURVEY SAMPLING}

Approximately 18,500 high school baseball coaches were contacted through email to participate in the online survey. Participant recruitment was conducted by the National High School Baseball Coaches Association and through access to the Clell Wade Coaches Online Directory. Both organizations have directories containing email addresses of thousands of high school baseball coaches throughout the United States. These organizations directly contacted the participants though their email database and provided them with the link to the survey.

The investigators of this study did not have access to participants' emails or any other personal identification information. Participation in the survey was voluntary and all responses to the survey were anonymous. Prior to beginning the survey, participants read the consent form and checked the "I agree" option if they wished to consent to the study. Participants were included in the study if they were willing and able to complete the online survey. Participants were excluded if they did not complete the required survey questions or selected the "I do not agree" to consent option prior to filling out the survey. Reponses to the online survey were prospectively collected for three consecutive months from February to April 2020. Approval from the institutional review boards at the University of Kentucky and the University of Evansville were obtained prior to data collection for this descriptive survey study.

\section{STATISTICAL METHODS}

According to the National Federation of State High School Associations, there are approximately 20,000 high school baseball coaches in the United States. Therefore, a sample size of 377 participants was needed to ensure the responses reflected the views of the population with a $95 \%$ confidence interval and a $5 \%$ margin for error. ${ }^{36}$ Descriptive statistics for nominal and ordinal data were summarized through frequencies and percentages and analyzed for differences with a one-way chi-square test. Cross tabulations and chi-square tests of independence were used to consider associations between use of arm care programs and coaching experience, age, and education level. An alpha level of $p<0.05$ was considered statistically significant for all tests. All data analyses were performed with SPSS statistical software (IBM SPSS Statistics for Mac, Version 26.0).

\section{RESULTS}

A total of 688 (3.7\%) high school baseball coaches throughout the United States responded to the online survey between February 3, 2020 and April 7, 2020. Of these 688 surveys, 34 were excluded due to insufficient completion of questions beyond the demographics section. Therefore, the remaining 654 surveys represented an inclusion rate of $96 \%$ $(654 / 688)$ and were used for data analyses. Demographic information for the coaches' age, years of coaching experience, educational level obtained, age of players coached, and level of players coached is displayed in Table 1.

\section{APPLICATION AND CHARACTERISTICS OF ARM CARE PROGRAMS}

In high school baseball coaches who responded to the survey, $87.3 \%(n=571 / 654)$ reported that they have their players perform an arm care program to maintain/improve upper extremity health (Table 2). Amongst the coaches who perform an arm care program, there were more coaches performing group-based programs $(81.4 \%, n=465 / 571)$ than individualized arm care programs $(18.6 \%, n=106 / 571)$ which were specific to the players' needs $(p<0.001)$ (Table 2). Overall, $85.2 \%(n=557 / 654)$ of coaches reported that they would be interested in an arm care screening tool to better inform their programs. Furthermore, $71.1 \%(n=59 / 83)$ of coaches who are not currently doing an arm care program would be interested in an arm care screening tool to guide their program $(p<0.001)$.

Chi-Square analysis revealed no significant relationship between the age of the high school baseball coach and whether the coach chose to use an arm care program with their players $(p=0.325)$. However, coaches over the age of 40 years were significantly more likely to design individualized arm care programs for their players compared to group-based programs $(p=0.002)$. Coaches with greater than seven years of coaching experience were significantly more likely to use an arm care program $(p<0.001)$ and individualize the program to address the specific needs of their players $(p<0.001)$. There was no significant relationship be- 
Table 1: Demographics of the High School Coaches

\begin{tabular}{|c|c|}
\hline Question & $\mathrm{n}(\%)$ \\
\hline \multicolumn{2}{|l|}{ How old are old? } \\
\hline$<20$ years & $0(0)$ \\
\hline $20-29$ years & $77(11.8)$ \\
\hline $30-39$ years & $190(29.1)$ \\
\hline $40-49$ years & 205 (31.3) \\
\hline$>50$ years & $182(27.8)$ \\
\hline \multicolumn{2}{|c|}{ What level of team do you coach? } \\
\hline Recreational team & $25(13.5)$ \\
\hline School team & $619(84.9)$ \\
\hline Traveling team & $5(0.8)$ \\
\hline Other & $5(0.8)$ \\
\hline \multicolumn{2}{|c|}{ What is the age of the baseball players you coach? } \\
\hline$<15$ years & $13(2.0)$ \\
\hline $15-18$ years & $636(97.4)$ \\
\hline $19-22$ years & $4(0.4)$ \\
\hline$>22$ years & $1(0.2)$ \\
\hline \multicolumn{2}{|c|}{ How many years have you been involved in coaching baseball? } \\
\hline$<1$ year & $5(0.8)$ \\
\hline $1-3$ years & $33(5.0)$ \\
\hline $4-6$ years & $80(12.2)$ \\
\hline $7-10$ years & $95(14.5)$ \\
\hline$>10$ years & $441(67.5)$ \\
\hline \multicolumn{2}{|c|}{ What is the highest education level you have achieved? } \\
\hline High school/GED & $7(1.1)$ \\
\hline Some college & $0(0)$ \\
\hline Bachelor of Science & $265(40.5)$ \\
\hline Master's degree & $303(46.3)$ \\
\hline Doctoral degree & $22(3.4)$ \\
\hline
\end{tabular}

tween use of arm care programs and the coaches' level of terminal degree achieved $(p=0.458)$ (Table 3).

\section{BARRIERS TO ARM CARE IMPLEMENTATION}

The coaches who did not perform arm care programs identified the largest barrier reported was not seeing the benefit of an arm care program $(41 \%, n=34 / 83)$ and not having enough staff to assist (31.3\%, n=26/83) (Figure 1). Only 11\% of 83 coaches reported that lack of time was a major barrier to implementing arm care exercises. Moreover, $96.6 \%$ $(\mathrm{n}=552 / 571)$ of coaches allow the players to perform arm care during practice time. Sixty percent $(n=342 / 571)$ of coaches consider 10-20 minutes of practice time dedicated to arm care exercises reasonable and $36.8 \%(n=205 / 571)$ encourage their players to perform their exercises $3 \mathrm{x} /$ week (Table 2).

\section{INJURY PREVENTION AWARENESS AND BELIEFS}

Most high school coaches (64.1\%, $n=366 / 571)$ who have their players perform arm care programs reported that the

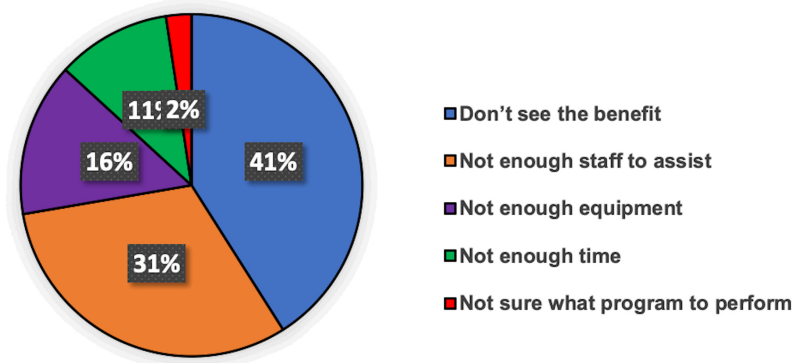

Figure 1: Coaches' ranking of greatest barriers to implementing an arm care program

main goal for the program is prevention of injuries (Figure 2). Among high school baseball coaches, 97.7\% $(n=639 / 654)$ either "strongly agree" or "agree" that injury risk factors should be monitored throughout the entire season (Table 4). However, when surveyed on which risk factors contributed most to pitching injuries, the majority of coaches 
Table 2: Arm Care Application and Characteristics

\begin{tabular}{|c|c|}
\hline Questions for Coaches & $\mathrm{n}(\%)$ \\
\hline \multicolumn{2}{|l|}{ Do you currently have your players perform a program to improve arm health? } \\
\hline Yes & $571(87.3)$ \\
\hline No & $83(12.7)$ \\
\hline \multicolumn{2}{|l|}{ Which of the following best describes your arm care program? } \\
\hline Group-based - general program that is similar to all players & $465(81.4)$ \\
\hline Individualized - each player receives different exercises specific to their needs & $106(18.5)$ \\
\hline \multicolumn{2}{|l|}{ Would you be interested in a 3-minute screen to help individualize your arm care program? } \\
\hline Yes & $557(85.2)$ \\
\hline No & $97(14.8)$ \\
\hline \multicolumn{2}{|l|}{ Should pitchers participate in an exercise program to improve/maintain arm health? } \\
\hline Yes & $570(99.8)$ \\
\hline No & $1(0.2)$ \\
\hline \multicolumn{2}{|l|}{ Do your players perform the arm care program during baseball practice time? } \\
\hline Yes & $552(96.6)$ \\
\hline No & $19(3.4)$ \\
\hline \multicolumn{2}{|c|}{ How many times per week do your players perform your arm care program during the season? } \\
\hline 1x/week & $9(1.6)$ \\
\hline $2 x /$ week & $79(14.2)$ \\
\hline $3 x /$ week & $205(36.8)$ \\
\hline $4 \mathrm{x} /$ week & $51(9.2)$ \\
\hline $5 x /$ week & $107(19.2)$ \\
\hline $6 x /$ week & $96(17.2)$ \\
\hline $7 x /$ week & $10(1.8)$ \\
\hline \multicolumn{2}{|l|}{ What time of year do you have your players perform your arm care program? } \\
\hline Preseason only & $7(1.2)$ \\
\hline Offseason only & $19(1.8)$ \\
\hline Start of season to end of season & $40(7)$ \\
\hline Preseason to end of season & $337(59)$ \\
\hline Year around & $177(31)$ \\
\hline
\end{tabular}

reported that reduced shoulder ROM was the largest contributor (42.4\%, $\mathrm{n}=277 / 651)$ followed by pitching $>8$ months per year $(33 \%, n=215 / 651)$. However, throwing with a fatigued arm and playing catcher as a secondary position were only identified as risk factors in $16.7 \%(n=109 / 651)$ and $2 \%(n=12 / 654)$ of coaches surveyed, respectively (Figure 3). Furthermore, $27.7 \%$ of 654 surveyed coaches were either "not sure" or "disagreed" that a previous injury increases risk for future injuries.

Overall, 98.3\% ( $\mathrm{n}=643 / 654)$ of high school baseball coaches believe that arm care programs can reduce throwing-related upper extremity injuries (Table 4). Furthermore, $57.3 \%(n=375 / 654)$ of high school baseball coaches reported that the coaches play the largest role in preventing baseball injuries. Interestingly, coaches believed that parents and medical professionals such as physical therapists, athletic trainers, and physicians play a much smaller role in preventing baseball injuries. Only $2.8 \%(n=18 / 654)$ of high school coaches believed that parents played the greatest role in injury prevention, whereas only $1.5 \%(n=10 / 654)$ of coaches believed that medical professionals were responsi-

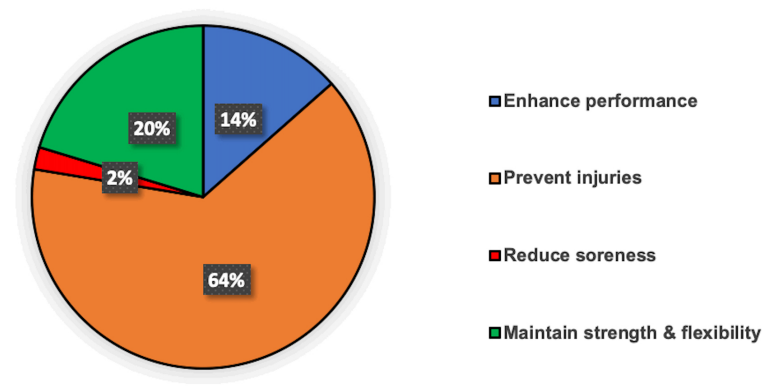

Figure 2: Coaches' response to the primary goal of their arm care program

ble (Figure 4). 
Table 3: Comparisons Between Coaches Demographics and Use of Arm Care Programs

\begin{tabular}{|c|c|c|c|}
\hline Questions & & & \\
\hline Is the age of the coach associated with use of arm care programs? & Yes & No & $P$ value \\
\hline$<40$ years & $85.8 \%$ & $14.2 \%$ & \multirow{2}{*}{0.325} \\
\hline$>40$ years & $88.4 \%$ & $11.6 \%$ & \\
\hline Is age associated with use of group vs. individualized arm care program & Group & Individual & $P$ value \\
\hline$<40$ years & $88.2 \%$ & $11.8 \%$ & \multirow{2}{*}{0.001} \\
\hline$>40$ years & $76.9 \%$ & $23.1 \%$ & \\
\hline Is coaching experience associated with use of arm care programs & Yes & No & $P$ value \\
\hline 1-6 years of experience & $72.9 \%$ & $27.1 \%$ & \multirow{2}{*}{$<0.001$} \\
\hline$>7$ years of experience & $90.5 \%$ & $9.5 \%$ & \\
\hline Is coaching experience related to use of group or individualized arm care? & Group & Individual & Pvalue \\
\hline 1-6 years of experience & $88.4 \%$ & $11.6 \%$ & \multirow{2}{*}{0.043} \\
\hline$>7$ years of experience & $80.2 \%$ & $19.8 \%$ & \\
\hline Is education level related to use of arm care programming & Yes & No & $P$ value \\
\hline No college degree & $84.4 \%$ & $15.6 \%$ & \multirow{2}{*}{0.458} \\
\hline College degree & $12.4 \%$ & $87.6 \%$ & \\
\hline Is education level related to use of group or individualized arm care & Group & Individual & $P$ value \\
\hline No college degree & $77.8 \%$ & $22.2 \%$ & \multirow[b]{2}{*}{0.467} \\
\hline College degree & $81.8 \%$ & $18.2 \%$ & \\
\hline
\end{tabular}

Table 4: Injury Prevention Awareness Survey Reponses

\begin{tabular}{|c|c|c|c|c|c|}
\hline & SA & A & NS & $\mathrm{D}$ & SD \\
\hline $\begin{array}{l}\text { Arm care programs can reduce elbow/shoulder injuries in high school baseball } \\
\text { pitchers? }\end{array}$ & $68 \%$ & $31 \%$ & $1.7 \%$ & $0 \%$ & $0 \%$ \\
\hline Having a previous injury will lead to an increased risk for a future injury? & $25 \%$ & $48 \%$ & $19 \%$ & $9 \%$ & $0 \%$ \\
\hline $\begin{array}{l}\text { Deficits in the hips and/or core can contribute to injuries of the shoulder or } \\
\text { elbow? }\end{array}$ & $45 \%$ & $42 \%$ & $13 \%$ & $0.5 \%$ & $0 \%$ \\
\hline Injury risk factors should be monitored throughout the entire season? & $71 \%$ & $27 \%$ & $2 \%$ & $0.3 \%$ & $0 \%$ \\
\hline
\end{tabular}

$\mathrm{SA}=$ strongly agree, $\mathrm{A}=$ agree, $\mathrm{NS}=$ not sure, $\mathrm{D}=$ disagree, $\mathrm{SD}=$ strongly disagree

\section{DISCUSSION}

The overarching purpose of this survey was to investigate the usage of arm care programs by high school baseball coaches to promote arm health. The results of the survey demonstrated greater than $87 \%$ of responding high school coaches implement arm care programs. From the perspective of the coach, the primary objective for arm care programming is to prevent injuries, but the results suggest that their injury prevention awareness and strategies are limited. The notion that arm care exercise programs can reduce injury incidence is not a novel concept as several prior studies have supported this outcome. ${ }^{10,30,32}$ Specifically, multimodal arm care programming has been shown to reduce the incidence of medial elbow injuries in youth baseball players by nearly $50 \% .{ }^{10,30}$ However, this is the first survey which has explored arm care and injury prevention from the perspective of the high school coach. Although $13 \%$ of coaches do not currently implement an arm care program,

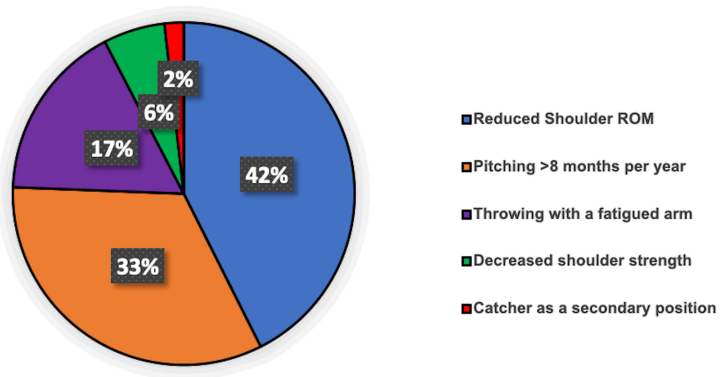

Figure 3: Coaches' ranking of risk factors which contribute most to pitching injuries

$71 \%(n=59 / 83)$ of those coaches are interested in using a screening tool to aid in designing a program.

The primary objective of this survey was to determine if coaches use group-based or individualized arm care pro- 
grams. It also sought to explore how the coaches' age, education, and experience level influenced the type of arm care programs implemented. The majority of high school baseball coaches who responded to this survey reported using group-based arm care programs. This is not surprising as the only arm care programs which have been explored in the current literature are group-based programs. ${ }^{10,30,32}$ Older and more experienced coaches tended to implement individualized arm care programs more so than younger coaches with less coaching experience. One possible explanation for this relationship could be that longer tenured coaches may have observed better player durability with individualized arm care programming. This may be due to the variability of different combinations of risk factors among individuals such as body mass index, biomechanics, or muscle flexibility. ${ }^{37}$ Furthermore, increasing the dosage of exercises designed to target a specific risk factor may maximize the outcome. ${ }^{37}$ To date there have been no studies which have evaluated individualized arm care programs in baseball players. However, in high school soccer players, Huebner et $\mathrm{al}^{37}$ reported that an individualized injury prevention program significantly lowered the injury risk in 21 out of 44 players. Baseball players may also benefit from individualized arm care exercises, but future research is needed to determine if targeting risk factors specific to the individual is more effective than group programming in this population.

The secondary purpose of this survey was designed to identify barriers that discouraged coaches from implementing arm care programs for their players. It was hypothesized that lack of time would be a major barrier to implementation, but only $11 \%(n=9 / 83)$ of responding coaches identified this as a limitation. Interestingly, $41 \%$ of 83 respondents not using arm care programs reported lack of benefit of the program as the primary reason. This is somewhat a paradoxical perspective as $98.3 \%$ of all coaches surveyed also agreed that arm care programs can reduce shoulder/elbow injuries. It is possible that coaches have been taught that arm care exercises can reduce injuries but are hesitant to buy in to program implementation due to lack of observed effectiveness.

The second most frequently cited barrier to arm care implementation reported by coaches surveyed was insufficient staff. This is not surprising as additional support staff in high school programs are typically limited due to marginalized budgets. ${ }^{38,39}$ However, researchers have shown that arm care exercises can reduce injury incidence in adolescent baseball players without additional staff or equipment. In a prospective cohort, Shitara et $\mathrm{al}^{32}$ reported a $36 \%$ reduction in upper extremity injury incidence in high school baseball players who performed posterior shoulder stretching. Likewise, Sakata et $\mathrm{al}^{30}$ found that a 10 -minute warm up program that targeted multiple physical risk factors reduced the incidence of medial elbow pain by nearly $50 \%$ in youth baseball players. Neither program by Shitara et $\mathrm{al}^{32}$ or Sakata et $\mathrm{al}^{30}$ required additional equipment and was performed independently by the players.

Finally, this survey explored high school baseball coaches' current awareness and beliefs of injury prevention. The responding high school coaches demonstrated variability in knowledge of risk factors and injury prevention measures. Whereas many coaches acknowledged that dysfunc-

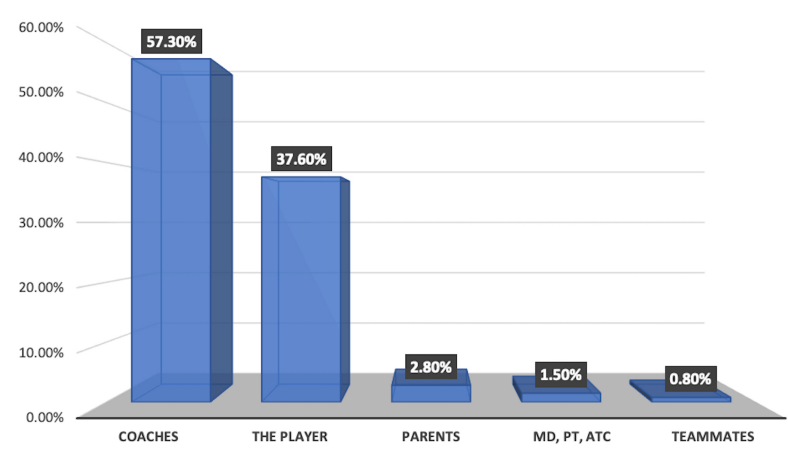

Figure 4: Coaches' response to who plays the greatest role in preventing baseball injuries

tion in hips and core can contribute to throwing related injuries, only $25 \%$ of coaches strongly agreed that previous injury can lead to a future injury. Research has suggested that a history of a previous injury is one of the strongest and most consistently reported risk factors for future injury. ${ }^{12,40-42}$ Also, reduced shoulder ROM was selected by high school coaches as the risk factor contributing the most to injury. Multiple studies have reported that limited shoulder ROM can contribute to increased injury in high school and professional baseball players. Specifically, Shanley et $\mathrm{al}^{8}$ reported that high school baseball players with $\geqslant 25^{\circ}$ glenohumeral internal rotation deficit (GIRD) were 4.8 times greater risk of having an upper extremity injury. Shitara et $\mathrm{al}^{32}$ reported that a $20^{\circ}$ GIRD was associated with 2.7 times greater odds for injury. In professional players, total shoulder range of motion differences of greater than $5^{\circ}$ have been significantly related to injury incidence. ${ }^{18}$ Although the responding coaches were able to successfully identify reduced shoulder ROM as a risk factor, it is concerning that far fewer coaches considered increased pitching volume as a major concern for arm injury.

In the current survey, only $17 \%(n=109 / 654)$ of respondents identified throwing with a fatigued arm as the primary injury risk factor. It was expected that pitching with arm fatigue would be identified as the greatest risk factor due to literature showing that throwing with a fatigued arm increases the odds of upper extremity injury 13-fold (95\% CI, 3.22 to 55.09). ${ }^{43}$ Throwing for greater than eight months of the year which has been shown to increase injury risk five-fold was identified as the primary risk factor in $33 \%$ of respondents. Hibberd et $\mathrm{al}^{16}$ reported that pitchers who also play catcher as a secondary position are nearly three times greater risk for injury but only $2 \%(n=12 / 654)$ of responding coaches identified this the primary risk factor. Research has shown that loss of shoulder strength during season may play a role in arm injury in baseball players. A study performed by Tyler et $\mathrm{al}^{9}$ on a sample of high school baseball players reported that preseason supraspinatus weakness increased the risk of having substantial injury resulting in missing greater than three games by four-fold (RR 4.6, $95 \% \mathrm{CI}, 1.4$ to 15.0$)$. However, despite this research, only $6 \%(n=38 / 654)$ of high school coaches ranked strength as the major contributor to injury. The coaches tended to focus on motion deficits of the shoulder perhaps because of 
the long-standing nature of this information but inconsistently reported throwing volume a major factor. This suggests that coaches may require updated education related to injury risk factors.

The results of those surveyed indicate that the majority of high school coaches accept the primary role of preventing baseball injuries. High school coaches feel that they can positively impact the health and well-being of their players more effectively than healthcare providers despite their poor knowledge of injury risk factors. In conjunction with the majority of coaches using arm care programs, it appears that time is not a limiting factor. In fact, responding coaches dedicate 10-20 minutes of practice time three times per week to arm care exercises. However, coaches and rehabilitation professionals could do a better job collaborating on risk factors and injury prevention strategies. Future research is needed to gain insight into the resources commonly used by coaches for injury prevention information. It is unlikely high school baseball coaches are aware of this medical literature which may explain why there is a disconnect between current medical literature and knowledge of high school coaches. This may make it difficult for high school coaches to implement and design effective arm care programs for their players. Collaborative efforts between rehabilitation professionals and coaches are needed to provide educational opportunities for injury prevention strategies. This may include providing up to date information in a location which is easily assessable and practically applicable for the coaches' everyday needs.

This study is not without limitations. First, these survey data were based on self-report which may have resulted in reporting bias by the responding coaches. Because the majority of responders were more positive in arm care program use, the coaches surveyed were likely biased toward this value. Additionally, the nature of the survey design cannot confirm actual practice therefore the results of the coaches' injury prevention knowledge could be skewed. Second, the authors used email to attempt to survey a geographically diverse sample of high school coaches throughout the United
States. However, technologic restrictions such as limited access to a computer or internet may have resulted in a selection bias. Lastly, while this survey did report on the usage of arm care programs, it did not specifically inquire about how effective the coaches felt these programs are at preventing injury.

\section{CONCLUSION}

The results of this survey suggest that the majority of high school baseball coaches implement group-based arm care exercise programs to prevent injury. Coaches who were older and more experienced were more likely to individualize their arm care programs. Lack of time is not a major barrier to implementation of arm care programming. High school coaches believe they are the most impactful at preventing baseball injuries and devote practice time multiple days per week to arm care exercises. However, the responding coaches exhibited inconsistent risk factor awareness and dated injury prevention beliefs. Therefore, better educational collaboration between rehabilitation professionals and high school coaches regarding injury risk factors and preventative strategies is warranted.

\section{ACKNOWLEDGEMENTS}

The authors would like to thank the National High School Baseball Coaches Association and Tim Saunders for allowing access to their coaches. None of the authors of this article have any conflicts of interest or financial conflicts to report.

Submitted: August 16, 2020 CDT, Accepted: November 26, 2020 CDT 


\section{REFERENCES}

1. Shanley E, Rauh MJ, Michener LA, Ellenbecker TS. Incidence of injuries in high school softball and baseball players. J Athl Train. 2011;46(6):648-654.

2. Fleisig GS, Andrews JR, Dillman CJ, Escamilla RF. Kinetics of baseball pitching with implications about injury mechanisms. Am J Sport Med. $1995 ; 23(2): 233-239$.

3. Atanda A, Averill LW, Wallace M, Niiler TA, Nazarian LN, Ciccotti MG. Factors related to increased ulnar collateral ligament thickness on stress sonography of the elbow in asymptomatic youth and adolescent baseball pitchers. Am J Sport Med. 2016;44(12):3179-3187. doi:10.1177/0363546516 $\underline{661010}$

4. Fleisig GS, Escamilla RF. Biomechanics of the elbow in the throwing athlete. Oper Tech Sports Med. 1996;4(2):62-68

5. McHugh MP, Tyler TF, Mullaney MJ, Mirabella MR, Nicholas SJ. The effect of a high pitch volume on musculoskeletal adaptations in high school baseball pitchers. Am J Sport Med. 2016;44(9):2246-2254. doi:1 $\underline{0.1177 / 0363546516650183}$

6. Lazu AL, Love SD, Butterfield TA, English R, Uhl TL. The relationship between pitching volume and arm soreness in collegiate baseball pitchers. Int J Sports Phys. 2019;14(1):97-106.

7. Lyman S, Fleisig GS, Andrews JR, Osinski ED. Effect of pitch type, pitch count, and pitching mechanics on risk of elbow and shoulder pain in youth baseball pitchers. Am J Sport Med. 2002;30(4):463-468. doi:1 $\underline{0.1177 / 03635465020300040201}$

8. Shanley E, Rauh MJ, Michener LA, Ellenbecker TS, Garrison JC, Thigpen CA. Shoulder range of motion measures as risk factors for shoulder and elbow injuries in high school softball and baseball players. Am J Sport Med. 2011;39(9):1997-2006.

9. Tyler TF, Mullaney MJ, Mirabella MR, Nicholas SJ, McHugh MP. Risk Factors for Shoulder and Elbow Injuries in High School Baseball Pitchers: The role of preseason strength and range of motion. Am J Sport Med. 2014;42(8):1993-1999. doi:10.1177/0363546514 $\underline{535070}$

10. Sakata J, Nakamura E, Suzuki T, et al. Efficacy of a prevention program for medial elbow injuries in youth baseball players. Am J Sport Med. 2018;46(2):460-469. doi:10.1177/0363546517738003
11. Harada M, Takahara M, Mura N, Sasaki J, Ito T, Ogino T. Risk factors for elbow injuries among young baseball players. J Shoulder Ebl Surg.

2010;19(4):502-507. doi:10.1016/j.jse.2009.10.022

12. Yukutake T, Nagai K, Yamada M, Aoyama T. Risk factors for elbow pain in Little League baseball players: a cross-sectional study focusing on developmental factors. J Sport Med Phys Fit. 2015;55(9):962-968.

13. Shitara H, Kobayashi T, Yamamoto A, et al. Prospective multifactorial analysis of preseason risk factors for shoulder and elbow injuries in high school baseball pitchers. Knee Surg Sports Traumatol Arthrosc. 2017;25(10):3303-3310. doi:10.1007/s0016 7-015-3731-4

14. Lyman S, Fleisig GS, Waterbor JW, et al. Longitudinal study of elbow and shoulder pain in youth baseball pitchers. Med Sci Sport Exer. 2001;33(11):1803-1810.

15. Olsen SJ II, Fleisig GS, Dun S, Loftice J, Andrews JR. Risk factors for shoulder and elbow injuries in adolescent baseball pitchers. Am J Sport Med. 2006;34(6):905-912. doi:10.1177/0363546505284188

16. Hibberd EE, Oyama S, Myers JB. Rate of upper extremity injury in high school baseball pitchers who played catcher as a secondary position. J Athl Train. 2018;53(5):510-513. doi:10.4085/1062-6050-322-16

17. Bakshi NK, Inclan PM, Kirsch JM, Bedi A, Agresta C, Freehill MT. Current workload recommendations in baseball pitchers: a systematic review. Am J Sport Med. 2020;48:229-241. doi:10.1177/036354651983101 $\underline{0}$

18. Wilk KE, Macrina LC, Fleisig GS, et al. Correlation of glenohumeral internal rotation deficit and total rotational motion to shoulder injuries in professional baseball pitchers. Am J Sport Med. 2011;39(2):329-335. doi:10.1177/0363546510384223

19. Bohne C, George SZ, Zeppieri G Jr. Knowledge of injury prevention and prevalence of risk factors for throwing injuries in a sample of youth baseball players. Int J Sports Phys Ther. 2015;10(4):464-475.

20. Knapik DM, Continenza SM, Hoffman K, Gilmore A. Youth baseball coach awareness of pitch count guidelines and overuse throwing injuries remains deficient. J Pediatr Orthop. 2018;38(10):623-628. doi:1 0.1097/bpo.0000000000001244 
21. Fazarale JJ, Magnussen RA, Pedroza AD, Kaeding CC, Best TM, Classie J. Knowledge of and compliance with pitch count recommendations: a survey of youth baseball coaches. Sports Health. 2012;4(3):202-204. d oi: $10.1177 / 1941738111435632$

22. Yukutake T, Yamada M, Aoyama T. A survey examining the correlations between Japanese little league baseball coaches' knowledge of and compliance with pitch count recommendations and player elbow pain. Sports Health. 2013;5(3):239-243. $\underline{\mathrm{d}}$ oi:10.1177/1941738113480341

23. Vance DD, Alexander FJ, Kunkle BW, Littlefield M, Ahmad CS. Professional and amateur pitchers' perspective on the ulnar collateral ligament injury risk. Orthop J Sports Med.

2019;7(6):2325967119850777. doi:10.1177/232596711 9850777

24. Zabawa L, Alland JA. Association Between Parental Understanding of Pitch Smart Guidelines and Youth Baseball Player Injuries. Orthop J Sports Med. 2019;7(5):2325967119846314. doi:10.1177/2325 $\underline{967119846314}$

25. Wilk KE, Yenchak AJ, Arrigo CA, Andrews JR. The advanced throwers ten exercise program: a new exercise series for enhanced dynamic shoulder control in the overhead throwing athlete. Phys Sportsmed. 2011;39(4):90-97. doi:10.3810/psm.2011.1 1.1943

26. Chaudhari AM, McKenzie CS, Pan X, Oñate JA. Lumbopelvic control and days missed because of injury in professional baseball pitchers. Am J Sport Med. 2014;42(11):2734-2740. doi:10.1177/036354651 4545861

27. Melugin HP, Leafblad ND, Camp CL, Conte S. Injury Prevention in Baseball: from Youth to the Pros. Curr Rev Musculoskelet Med. 2018;11(1):26-34. doi:1 0.1007/s12178-018-9456-5

28. USA Baseball Medical and Safety Advisory Committee. Position Statement on Youth Baseball.

29. MLB. Major League Baseball. Pitch Smart.

30. Sakata J, Nakamura E, Suzuki T, et al. Throwing injuries in youth baseball players: can a prevention program help? a randomized controlled trial. Am J Sport Med. 2019:363546519861378. doi:10.1177/0363 $\underline{546519861378}$

31. Sakata J, Nakamura E, Suzuki T, et al. Efficacy of a prevention program for medial elbow injuries in youth baseball players. Am J Sport Med. 2018;46:460-469. doi:10.1177/0363546517738003
32. Shitara H, Yamamoto A, Shimoyama D, et al. Shoulder stretching intervention reduces the incidence of shoulder and elbow injuries in high school baseball players: a time-to-event analysis. Sci Rep. 2017;7:45304-45304. doi:10.1038/srep45304

33. Andersson SH, Bahr R, Clarsen B, Myklebust G. Preventing overuse shoulder injuries among throwing athletes: a cluster-randomised controlled trial in 660 elite handball players. Br J Sports Med. 2017;51(14):1073-1080. doi:10.1136/bjsports-2016-09 $\underline{6226}$

34. McHugh ML. Interrater reliability: the kappa statistic. Biochem Med. 2012;22(3):276-282.

35. Tavakol M, Dennick R. Making sense of Cronbach's alpha. Int J Med Educ. 2011;2:53-55. doi:1 $0.5116 /$ ijme.4dfb.8dfd

36. Qualtrics. Qualtrics Sample Size Calculator.

37. Huebner BJ, Plisky PJ, Kiesel KB, SchwartzkopfPhifer K. Can injury risk category be changed in athletes? an analysis of an injury prevention system. Int J Sports Phys Ther. 2019;14(1):127-134.

38. Lindblom H, Carlfjord S, Hägglund M. Adoption and use of an injury prevention exercise program in female football: A qualitative study among coaches. Scand J Med Sci Sports. 2018;28(3):1295-1303. doi:1 $\underline{0.1111 / \text { sms.13012 }}$

39. Yard EE, Collins CL, Comstock RD. A comparison of high school sports injury surveillance data reporting by certified athletic trainers and coaches. $J$ Athl Train. 2009;44(6):645-652. doi:10.4085/1062-605 0-44.6.645

40. Sutter EG, Orenduff J, Fox WJ, Myers J, Garrigues GE. Predicting injury in professional baseball pitchers from delivery mechanics: a statistical model using quantitative video analysis. Orthopedics. 2018;41(1):43-53. doi:10.3928/01477447-20171127-0 $\underline{5}$

41. Matsuura T, Iwame T, Suzue N, Arisawa K, Sairyo K. Risk factors for shoulder and elbow pain in youth baseball players. Phys Sportsmed. 2017;45(2):140-144. doi:10.1080/00913847.2017.1300505

42. Agresta CE, Krieg K, Freehill MT. Risk factors for baseball-related arm injuries: a systematic review. Orthop J Sports Med. 2019;7(2):2325967119825557. do i: $10.1177 / 2325967119825557$

43. Salamh P, Jones E, Bashore M, Liu X, Hegedus EJ. Injuries and associated risk factors of the shoulder and elbow among adolescent baseball pitchers: A systematic review and meta-analysis. Phys Ther Sport. 2020;43:108-119. doi:10.1016/j.ptsp.2020.02.013 


\section{SUPPLEMENTARY MATERIALS}

\section{Appendix 1}

Download: https://ijspt.scholasticahq.com/article/24247-a-nation-wide-survey-of-high-school-baseball-coachesperceptions-indicates-their-arm-care-programs-play-a-role-in-injury-prevention/attachment/61309.docx 